\title{
Development of low pressure reverse osmosis membrane for desalination process
}

\begin{abstract}
Water shortage has become a real problem at global level and therefore, new and innovative technologies were established to provide sustainable solutions to water crisis. One of the effective approaches to resolve the global challenges is introducing the membranebased desalination. Reverse Osmosis (RO) is a pressure driven membrane process which becoming increasingly popular and widely used for water purification applications that require high salt rejection such as brackish and seawater desalination. In this study, the influence of Sodium dodecyl sulphate (SDS) surfactant in producing the finest membrane for desalination were investigated in terms of performance, morphological structure and molecular orientation. From a polymer blending of polysulfone (PSF)/N-Methyl-2Pyrrolidone (NMP)/polyvinylpyrrolidone (PVP)/sodium dodecyl sulphate (SDS) were formulated for making of low pressure reverse osmosis (LPRO) membrane. In order to examine the influence of SDS surfactant, different concentration from $0 \mathrm{wt} \%$ to $3 \mathrm{wt} \%$ were employed for desalination application of 10,000ppm (brackish water) and $50000 \mathrm{ppm}$ (seawater). Experimental data showed that the increasing of $0.5 \mathrm{wt} \%$ in surfactant produced higher pure water permeation (PWP) and flux. At $2.5 \mathrm{wt} \%$ of SDS, the LPRO membranes showed the highest PWP of about $44.8 \mathrm{~L} / \mathrm{m}^{2} \mathrm{~h}$ and brackish water flux at $45.58 \mathrm{~L} / \mathrm{m}^{2} \mathrm{~h}$. Meanwhile, at $3.0 \mathrm{wt} \%$, the highest flux of seawater at $39.37 \mathrm{~L} / \mathrm{m}^{2} \mathrm{~h}$ was obtained. Moreover, the optimized LPRO ( $2 \mathrm{wt} \%$ of SDS) membrane performed high rejection ratio of $90.9 \%$ for brackish water and $90.4 \%$ for seawater concentration of $10,000 \mathrm{ppm}$ and $50,000 \mathrm{ppm}$, respectively. Therefore, the findings revealed that the fabricated LPRO membrane having a good potential to be used as eco-efficient desalination process of brackish water and seawater technology.
\end{abstract}

Keywords: low pressure reverse osmosis, surfactant, desalination, morphologies, molecular orientation
Volume 4 Issue 3 - 2019

\author{
Al Dabbaas Khuzama Mansoor A,' Abdul \\ Rahman Hassan, ${ }^{1,2}$ Nor Azirah Sulaiman,' \\ Nurul Hannan Mohd Safari,' Sabariah Rozali' \\ 'East Coast Environmental Research Institute (ESERI), Universiti \\ Sultan Zainal Abidin, Gong Badak Campus, Malaysia \\ ${ }^{2}$ Faculty of Industrial Design and Technology (FRIT), Universiti \\ Sultan Zainal Abidin, Gong Badak Campus, Malaysia
}

Correspondence: Abdul Rahman Hassan, East Coast Environmental Research Institute (ESERI), Universiti Sultan Zainal Abidin, Gong Badak Campus, 21300 , Kuala Nerus, Terengganu, Malaysia, Tel +609-6688069, Fax +609-6688707, Email rahmanhassan@unisza.edu.my

Received: May 29, 2019 | Published: June 24, 2019
Abbreviations: PSF, polysulfone; NMP, N-Methyl-2Pyrrolidone; PVP, polyvinylpyrrolidone; SDS, sodium dodecyl sulphate; (SDS); PWP, pure water permeation; LPRO, low pressure reverse osmosis; RO, reverse osmosis; SEM, scanning electron microscope; FTIR, fourier-transform infrared; A, effective membrane area $\left(\mathrm{m}^{2}\right)$; Cf, concentration of feed $(\mu \mathrm{S} / \mathrm{cm})$; $\mathrm{Cp}$, concentration of permeate $(\mu \mathrm{S} / \mathrm{cm})$; Jv, permeate flux $\left(\mathrm{L} / \mathrm{m}^{2} \mathrm{~h}\right) ; \mathrm{ppm}$, part per million; $\mathrm{R}$, rejection; t, time (h); V, volume of permeate solution collected (L).

\section{Introduction}

Over the past decades, there are many countries in the world suffering from a shortage of natural fresh water. The rise in global population rates together with the expansion of industrial and agricultural activities have led to a dramatic increase in requirement of fresh water. ${ }^{1}$ Sandia defined that fresh water is containing less than $1000 \mathrm{mg} / \mathrm{L}$ of salts or total dissolved solids (TDS). ${ }^{2}$ For above $1000 \mathrm{mg} / \mathrm{L}$, properties such as taste, color, corrosion propensity, and odor can be adversely affected. Available fresh-water resources from rivers and groundwater are presently limited and are being increasingly depleted at an alarming rate in many places. Due to population growth and increasing demand for water, new methods to create clean water have to be found. Conventional sources for fresh water such as rivers, lakes, and groundwater are overused or misused.

Akili and co-workers claimed that, seawater is unsuitable for human consumption and for industrial and agricultural uses. ${ }^{3}$
Membrane-based seawater desalination and wastewater reuse are widely considered as promising solutions to augment water supply and alleviate water scarcity. ${ }^{4,5}$ Now membrane processes are an efficient and reliable way to treat water and they have become better functioning and more cost effective than they were a few years ago. Reverse osmosis (RO) is one of established process and the leading technology for the desalination process of saline water which purify water by separating the dissolved solids from feed stream resulting in permeate and reject stream for a wide range of applications in domestic as well as industrial applications. ${ }^{6-8}$

Polymeric reverse osmosis (RO) membranes have dominated commercial applications for desalination due to their low-cost fabrication, ease of handling and improved performance in selectivity and permeability. Nowadays membrane applications spread over various industries including medical sector. ${ }^{9}$ For industry, low pressure reverse osmosis (lower than 100 bar of pressure required) is suggested to be used as an alternative as the lower pressure operation is very attractive in reducing capital and operation cost. It also can provide an easier method for the system maintenance and then achieve energy saving. Murthy and Choudhari ${ }^{10}$ studied the paper on the treatment of distillery spent wash where ultrafiltration (UF) and RO membranes on pilot plant uses thin film composite for purification of the wastewater for removal of colour and the contaminants. The obtained result indicates the suitability of RO for reducing freshwater consumption by recycling water which will minimize the waste disposal costs and reduction in regulatory pressure. 
The desalination performance of RO membrane depends largely on the membrane material and the membrane structure. An industrially useful RO membrane must exhibit several characteristics such as high water flux, high salt rejection, mechanical stability, tolerance to temperature variation, resistance to fouling, and low cost. So far, a number of polymer materials have been used to make RO membranes. ${ }^{11}$ In this study, PSF had been used to produce LPRO membrane.

Polysulfone is a polymer widely used as a membrane material for liquid separation processes such as ultrafiltration and reverse osmosis. It consist both aliphatic and aromatic polymers that widely used as membrane since PSF has good resistant to high temperatures, good mechanical and chemically stable. ${ }^{12}$ These criteria make PSF the best membrane materials for separation process. The good solubility allows extensive uses of PSF membranes, with special emphasis on phase inversion by immersion precipitation. ${ }^{13}$ However, PSF exhibit two main disadvantages which are the hydrophobic character and the low resistances to UV radiation. Thus, suitable materials need to be introduced in the casting solution in order to prepare membranes with excellent penetration properties.

The modification of LPRO membranes can be improved by the addition of small amount of additives into the casting solution as it can control the membrane formation. Various inorganic (such as $\mathrm{LiCl}$ ) and high molecular weight organic such as polyvinyl pyrrolidone (PVP) or polyethylene glycol (PEG) additives to casting solution are often used. ${ }^{14} \mathrm{PVP}$ and PEG are the most important polymeric additives used in study and evaluate the membranes performances. This is because they are miscible with the most of the membrane materials and are soluble in both aqueous and many organic media. ${ }^{15}$ Ochoa and coauthor confirmed that the addition of PVP to the casting solution increases the UF-PES membrane permeability without significant changes in selectivity. ${ }^{16}$ Marchese and team reported that an increment in the pore density, a decrease of the effective thickness of the dense layer due to macrovoids in the support layer and an increment in the hydrophilicity of the surfaces on the membrane and inside the pores are the reasons behind the increase of membrane permeability when PVP is added..$^{17}$

Furthermore, one of the effective strategies to produce membrane with high performance in separation process is introducing surfactant as a new material in the casting solution. Since surfactant as additive were found to affect the performance and morphological structures of membrane, the potential of the surfactant towards production of newly LPRO membrane was studied. In this study, the effects of anionic surfactant (SDS) on the performance, morphology and orientation of the newly LPRO membrane was investigated. In context of application in water desalination, at different range of salt concentration, the effectiveness of LPRO was studied. Moreover, this study also provided a length of study towards the determination the best technical specification of asymmetric membrane to be used for desalination application. Ultimately, this research shows potential in generating an important knowledge on the roles of surfactant and major effects which is truly beneficial towards the advancement in membrane fabrication principle for the production of new membrane for different application in the future.

\section{Material and methods}

\section{Materials}

The starting materials, Polysulfone (PSF (Udel-P1 700); from Solvay), N-methyl-2-pyrrolidone (NMP; from Merck), Polyvinylpyrrolidone (PVP (K29-32); from Across Organics) and Sodium dodecyl sulphate (SDS; supplied by Fisher Scientific UK) were used for fabrication of LPRO membranes. Ethanol and n-hexane were used for pre-treatment step. Sodium chloride $(\mathrm{NaCl}$; from Merck) also included in material selection as to study the performance of salt rejection.

\section{Preparation of LPRO membranes}

In this study, Table 1 shows the dope formulation solution of the PSF dissolved in NMP was prepared using PVP as additive and different surfactants by stirring for $8 \mathrm{~h}$ at room temperature. The homogenous dope solution of membranes were cast on a glass plate using casting knife and having the thickness about $150 \mu \mathrm{m}$. Subsequently, the membranes were immersed into water for immersion precipitation process and remained for $24 \mathrm{~h}$ in order to ensure complete phase separation. For solvent-exchange process, membranes were immersed in ethanol for $24 \mathrm{~h}$ and $n$-hexane for $3 \mathrm{~h}$. Then, the membranes were ready to be used after drying process for $24 \mathrm{~h}$.

Table I The dope formulation

\begin{tabular}{llll}
\hline $\begin{array}{l}\text { NMP } \\
\text { (wt\%) }\end{array}$ & $\begin{array}{l}\text { PSF } \\
(w t \%)\end{array}$ & $\begin{array}{l}\text { PVP } \\
\text { (wt\%) }\end{array}$ & $\begin{array}{l}\text { SDS } \\
\text { (wt\%) }\end{array}$ \\
\hline 76 & 21 & 3 & 0 \\
75 & 21 & 3 & 1 \\
74.5 & 21 & 3 & 1.5 \\
74 & 21 & 3 & 2 \\
73.5 & 21 & 3 & 2.5 \\
73 & 21 & 3 & 3
\end{tabular}

Note:NMP,N-methyl-2-pyrrolidone;PSF,polysulfone;PVP,polyvinylpyrrolidone; SDS, sodium dodecyl sulphate

\section{Membrane performance evaluation}

The reverse osmosis (RO) filtration setup was used to investigate the desalination performances of seawater in terms of pure water permeation (PWP), flux and salt rejection. The membrane area for the LPRO membrane system was $1.38 \times 10^{-3} \mathrm{~m}^{2}$ with pressure of 5 bars. The testing was begin using deionized water pressured at 5 bars for compaction at least $30 \mathrm{~min}$. then, the test were carried out with aqueous solution containing $10,000 \mathrm{ppm}$ and $50,000 \mathrm{ppm}$ which presenting the brackish water and seawater, respectively. The water permeability of the prepared membranes can be described based on equation (1):

$$
J w=\frac{Q}{A t}
$$

Where $\mathrm{Q}$ is the volume permeation (liter), $\mathrm{A}$ is the effective area of the membrane for permeation $\left(\mathrm{m}^{2}\right)$ and $t$ is the time interval (hour). In addition, the flux and salt rejection for the RO system were calculated using the Equations (2) and (3), respectively.

$$
J v=\frac{v}{A t}
$$

Where $\mathrm{Jv}$ is the permeate flux of solution, $\mathrm{V}$ is the volume of permeate solution collected (liter), A is the effective area of membrane $\left(\mathrm{m}^{2}\right)$ and $\mathrm{t}$ is the time (hour). 


$$
R(\%)=\left(1-\frac{C_{p}}{C_{f}}\right) \times 100
$$

Where $\mathrm{R}$ is rejection of salt in percentage and $C_{p}$ and $C_{f}$ are the concentration of permeate and feed water, respectively. The salt concentration was investigated by measuring the electrical conductivity of the salt solution using a conductivity meter (SensION EC5, HACH Instrument).

\section{Morphology evaluation}

Analytical scanning electron microscopes (SEM, JSM 6360LA) was used to observed the morphology of the LPRO membranes. The cross-sectional views were examined as the membranes were immersed and fractured in liquid nitrogen, then sputter-coated with gold for producing electric conductivity.

\section{Molecular orientation evaluation}

The orientation of molecule in LPRO membrane samples were examined by transmission Variance 3100 Fourier-transform infrared (FTIR) Excalibur series. The analysis was done to study the functional group of the membrane. The sample was mounted into the sample holder with 'skin layer' facing the infrared (IR) beam. The spectra were recorded with cumulating 32 scans in total within the wave number of $4000-400 \mathrm{~cm}^{-1}$. The analysis was performed at $4 \mathrm{~cm}^{-1}$ of resolution.

\section{Results and discussion}

\section{Performance of LPRO membranes}

Membrane formulation greatly influenced the performance of RO membrane. Composition of the surfactant in membrane solution will affect the performance of the resultant membrane. The SDS concentration was varies from $1 \mathrm{wt} \%$ to $3 \mathrm{wt} \%$. The pure water permeability of the membranes was investigated using distilled water under 5 bars operating pressure. From the result obtained in Figure 1, at $1 \mathrm{wt} \%$ of SDS, the fabricated membrane produced the permeability about $15.11 \mathrm{~L} / \mathrm{m}^{2} \mathrm{~h}$. By increasing $0.5 \mathrm{wt} \%$ of surfactant concentration in the casting solution, the PWP increased and reached the maximum value of about $44.8 \mathrm{~L} / \mathrm{m}^{2} \mathrm{~h}$ at $2.5 \mathrm{wt} \%$ of SDS. At $3 \mathrm{wt} \%$, PWP showed an inverse trend of permeability with reduction of about $57.4 \%$. Addition of high amount of surfactant concentration leads to higher viscosity of solution which inhibits the penetration of non-solvent and weaken macrovoid formation and therefore, resulting in decreasing of membrane porosity and permeability. ${ }^{18,19}$

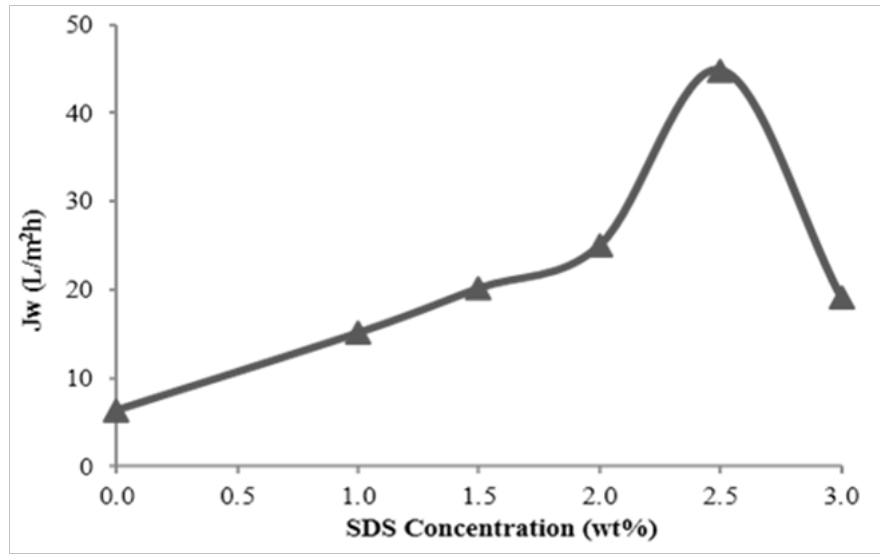

Figure I Pure water permeation of LPRO membranes.
The fabricated membranes (PSF/NMP/PVP/SDS) were then evaluated for the performance. The influence of anionic surfactant on brackish water flux and rejections is depicted in Figure 2. It was clearly showed that membrane with $2.5 \mathrm{wt} \%$ of SDS, shows the highest value of flux of about $45.58 \mathrm{~L} / \mathrm{m}^{2} \mathrm{~h}$ among all of other membranes. The addition of small amount of SDS surfactant promotes higher porosity of membrane sub-layer which determined higher water flux. ${ }^{20,21}$ Moreover, the fabricated membranes shows the improvement of salt rejection from $85.7 \%$ (without SDS) up to $88 \%$ in the presence of $1 \mathrm{wt} \%$ of surfactant. The increasing concentration of surfactant up to $2 \mathrm{wt} \%$ produced the maximum salt rejection value of about $90.9 \%$.

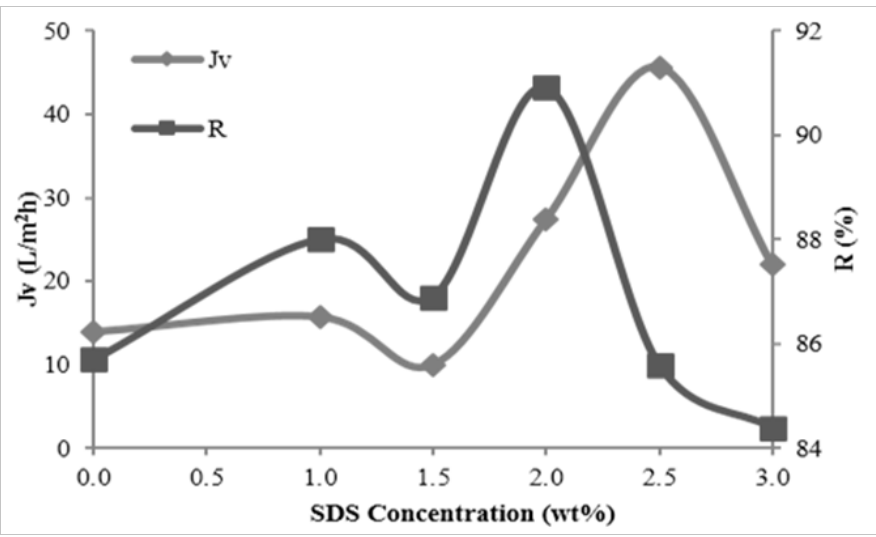

Figure 2 Effect of SDS concentration on flux and rejection of brackish water.

The effect of SDS concentration on flux and rejection of seawater are shown in Figure 3. It can be seen from that the flux of all fabricated membranes were increased gradually and achieved the highest value of about $39.37 \mathrm{~L} / \mathrm{m}^{2} \mathrm{~h}$ at $3 \mathrm{wt} \%$ of SDS. This is because the increment of SDS surfactant makes the membranes structure more porous in terms of formation of larger macrovoids which leads to higher volume of water flux produced. ${ }^{18}$ Same study by Rahimpour and his group reported that the small addition of surfactants (SDS, $\mathrm{CTAB}$ and Triton $\mathrm{X}-100)$ into casting solution increases the porosity of the membrane support layer which enhances pure water flux and milk concentration. ${ }^{22}$ As presented in Figure 3, the salt rejection for 50 $000 \mathrm{ppm}$ generally increased as the polymer concentration increased. The maximum value of the rejection is about $90.4 \%$ at $2 \mathrm{wt} \%$ of SDS. Nevertheless, the rejection started to decrease to $88.74 \%$ and $86.92 \%$ as the concentration of the surfactant increased to $2.5 \mathrm{wt} \%$ and $3.0 \mathrm{wt} \%$, respectively. This phenomenon might due to the anionic surfactant at higher concentrations interfered with the interfacial polymerization which deteriorating the structure of the fabricated membranes.

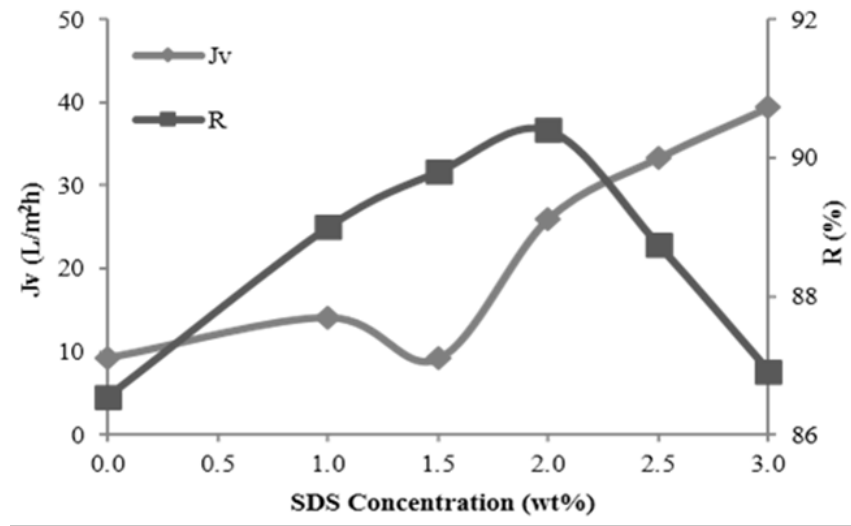

Figure 3 Effect of SDS concentration on flux and rejection of seawater. 
From Figure 2 and Figure 3, $2 \mathrm{wt} \%$ is the optimum concentration of SDS for the membranes as it depicted the maximum rejection of salt in brackish and seawater analysis. The optimal performance of the membranes at this point might be due to the increasing of membrane porosity and lower skin layer thickness, thus, resulting in the increment of permeability rate. ${ }^{18}$

\section{Morphological study of LPRO membranes}

The surface morphology of the polysulfone membranes with different concentration of SDS was shown in Figure 4 (a)-(f). The SEM images indicated that the addition of surfactant causes an increase in the formation of micro and macrovoids, depending on the use of surfactant concentration. In this study, all the fabricated membranes exhibit asymmetric structures with a combination of two layers, which are active layer and supporting layer that have significant role in membrane performance.
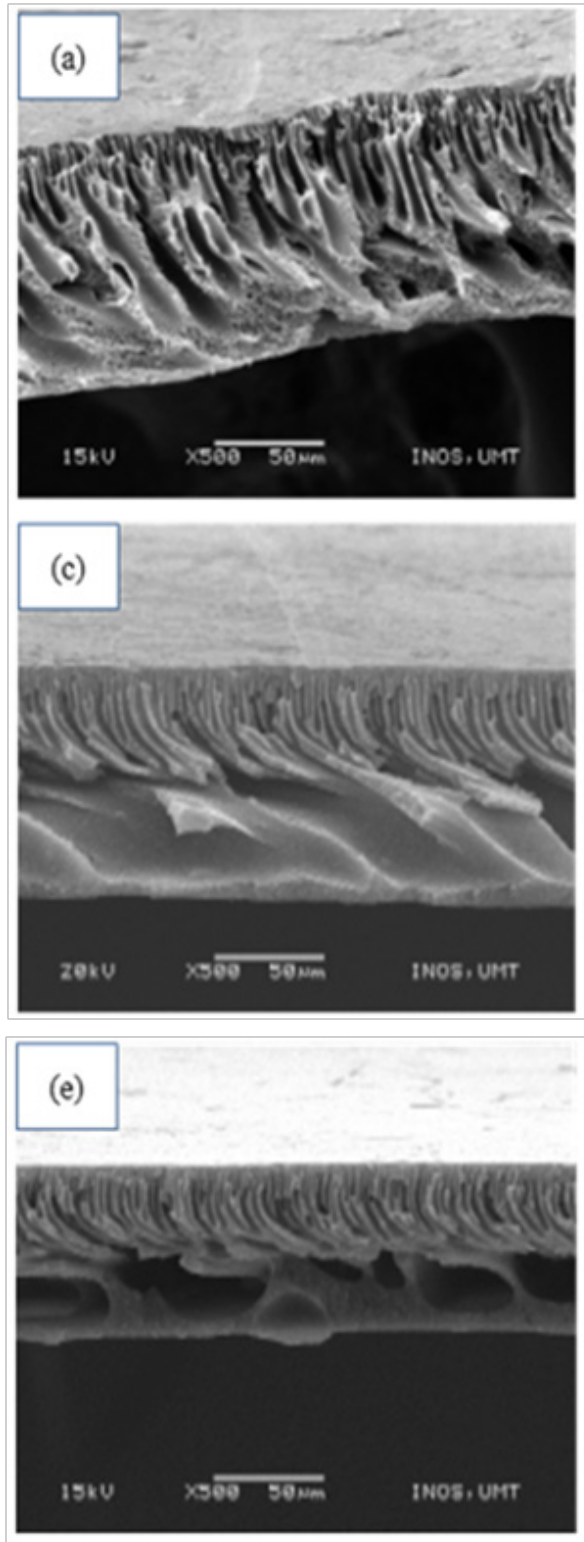

SEM cross-sectional images of membrane without surfactant were shown in Figure 4(a). It revealed a skin layer that was welldeveloped and supported by a porous support layer with large fingerlike structure and microvoids. In Figure 4(b), at $1 \mathrm{wt} \%$ of surfactant, the fabricated membrane formed macrovoids and finger-like structure were improved compared with the membrane without surfactant. This might be due to the addition of surfactant in the dope formulation as the molecule distribute freely in solvent and because of high polymer concentration which was $21 \mathrm{wt} \%$, the others could form micelle-like polymer-surfactant complex..$^{23,24}$ Fadilah and Hassan ${ }^{25}$ stated that composition of surfactant in membrane solution will affect the performance of the membrane as it plays a significant role in improving macrovoid structure and thickness. ${ }^{25}$ Usually, the large finger-like structure and macrovoid are formed when the coagulation process is faster. ${ }^{26}$
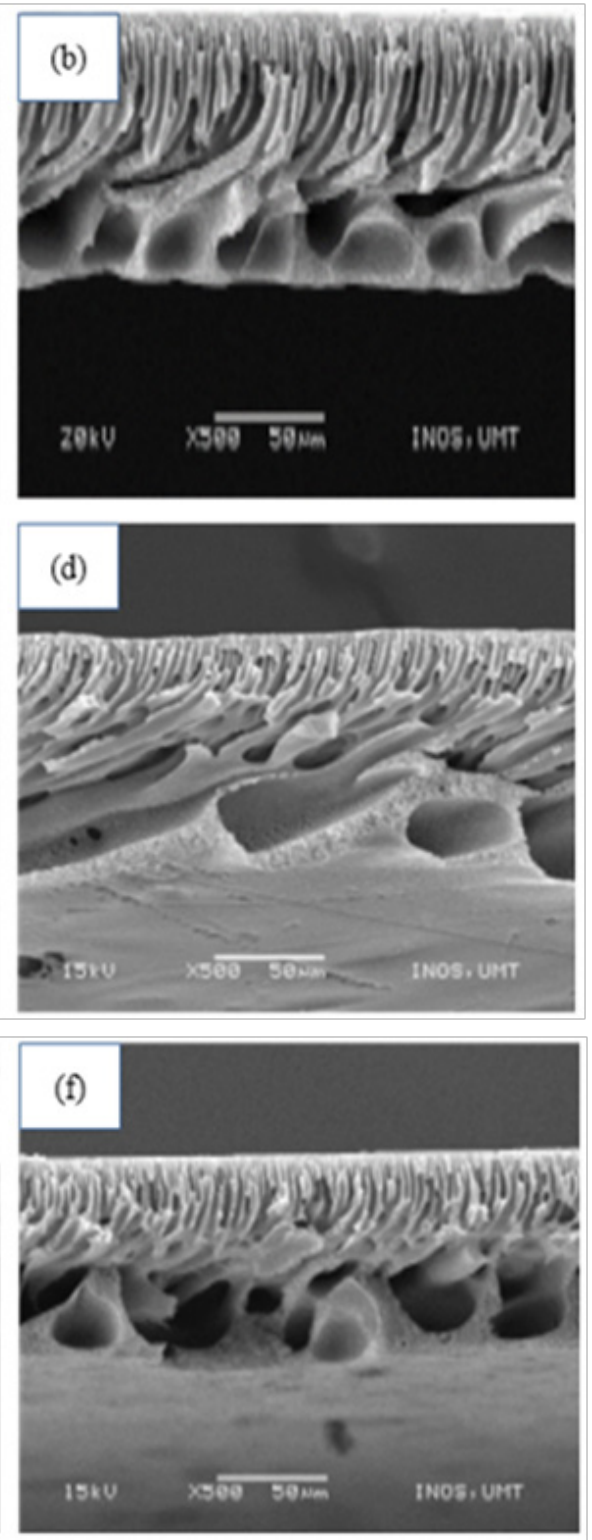

Figure 4 SEM cross-sectional images of LPRO membranes prepared with different concentration of SDS: (a) $0 w t \%$ (b) I wt \% (c) $1.5 w t \%$ (d) $2 w t \%$ (e) $2.5 w t \%$ (f) $3 w t \%$. 
Meanwhile, Figure 4(c) shows that the presence of $1.5 \mathrm{wt} \%$ of SDS surfactant produced a thicker top layer and suppressed the macrovoids. This phenomenon might related to the finding of Saedi and co-workers which mentioned that molecules can form free micelles at higher concentration of SDS and they preferred to form free micelles rather than to form a polymer-surfactant complex, so the formation of micelle-like polymer-surfactant complex suppresses. ${ }^{18}$ In particular, membrane in Figure 4(d) produced larger size of macrovoids as compared to other membranes, hence, improved the permeability performance which might be contributed by larger pore size of the membrane. ${ }^{27}$ This optimal performance membrane exhibits characteristics morphology of asymmetric membrane which consisted of a dense top layer and porous sub-layer. ${ }^{28}$ Zainal and team mentioned that SDS makes the membrane more porous as it formed larger macrovoids. ${ }^{29}$
Figure 4(e) and Figure 4(f) demonstrated of membranes with surfactant concentration at $2.5 \mathrm{wt} \%$ and $3 \mathrm{wt} \%$, respectively. The morphology analysis revealed that denser top layer and fully develop finger-like structure were formed. Furthermore, the result shows that, there were an increasing number of pores produced in the membranes as compared to the membrane of lower surfactant concentration. The spongy structure of the membranes gradually becomes compacted. It reduced the porosity of membrane support layer and resulted in lower PWP and salt performance.

\section{Molecular orientation study of LPRO membranes}

Figure 5 and Figure 6 shows the FTIR spectrum of membrane without surfactant and membrane with optimal performance of desalination at $2 \mathrm{wt} \%$ of surfactant, respectively. FTIR plays a decisive role in order to study the intermolecular interaction between the molecules in the membrane.

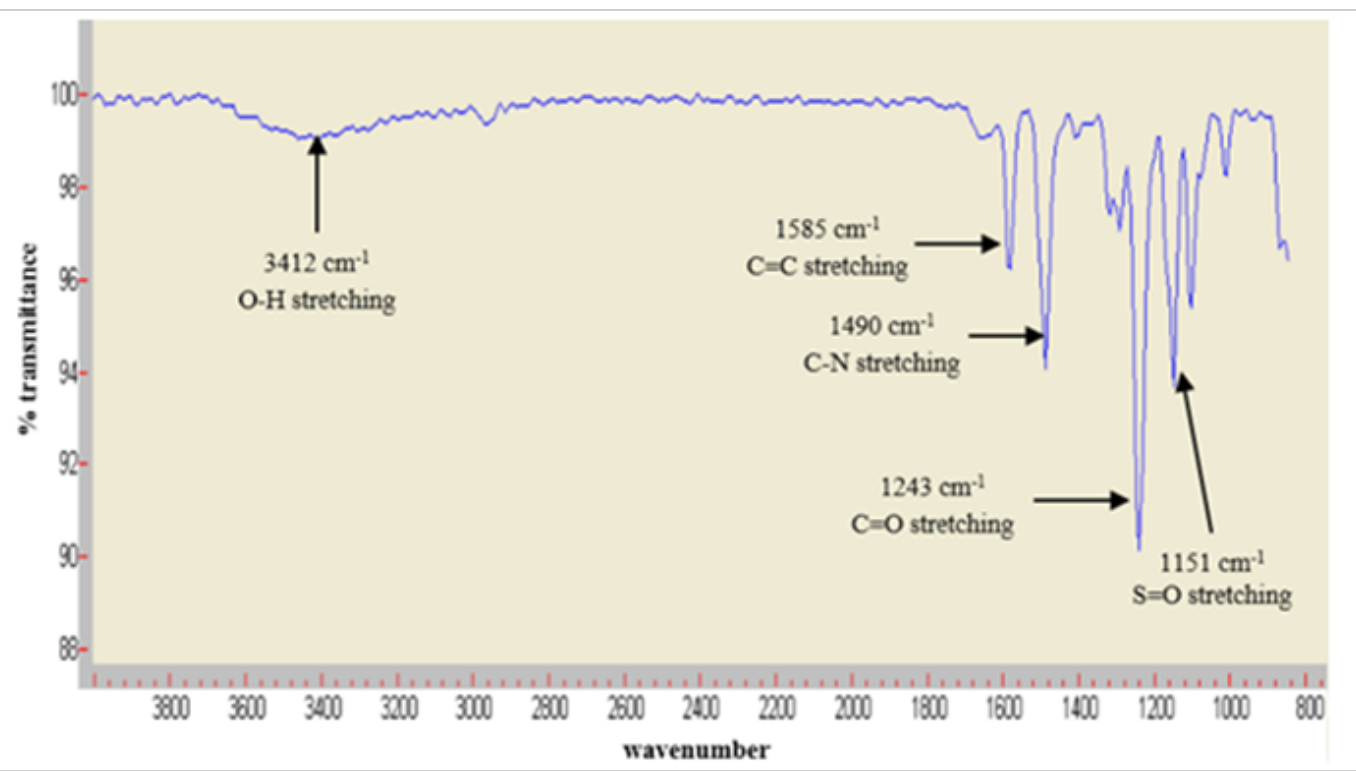

Figure 5 FTIR spectrum for membrane without surfactant.

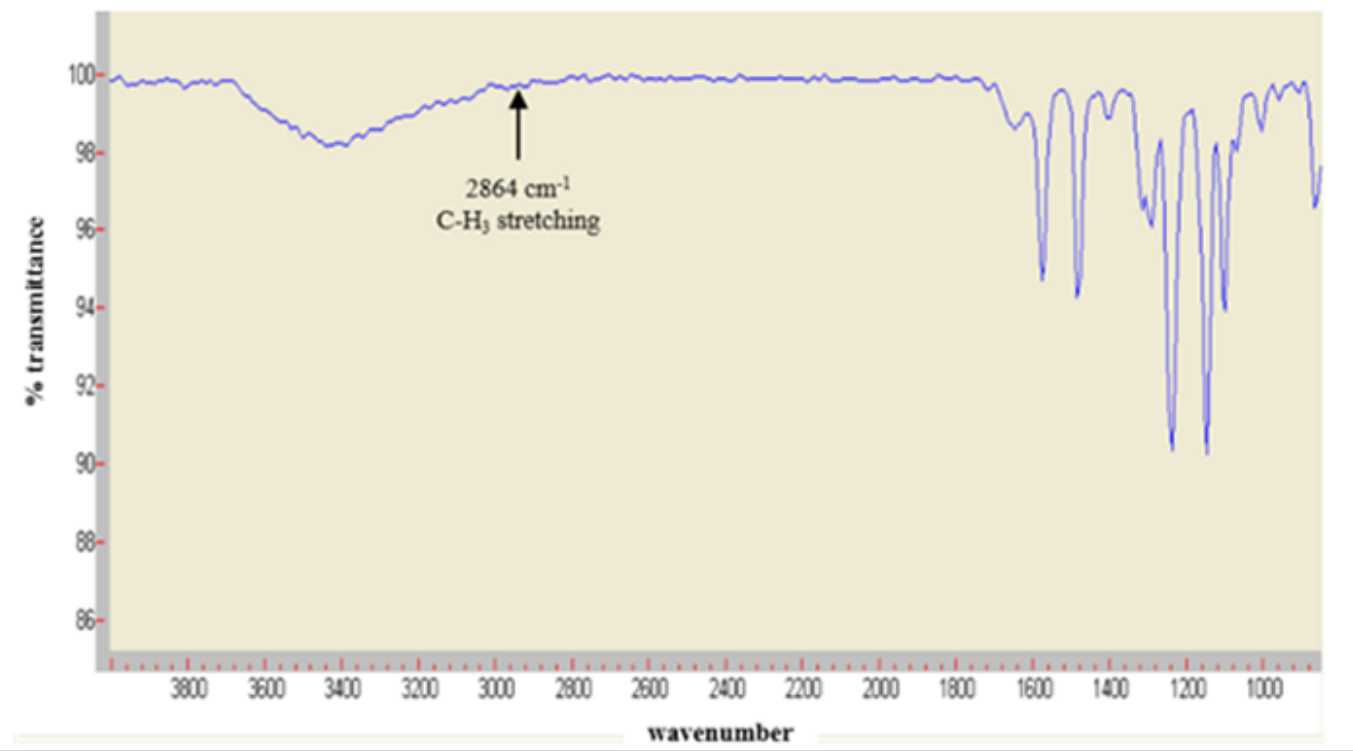

Figure 6 FTIR spectrum for membrane with surfactant. 
In Figure 5, the spectrum of membrane without surfactant shows the transmittance band observed near $3412 \mathrm{~cm}^{-1}$ which assigned to $\mathrm{O}-\mathrm{H}$ stretching vibration of PSF polymer. The presence of aromatic $\mathrm{C}=\mathrm{C}$, $\mathrm{C}=\mathrm{O}$ and $\mathrm{S}=\mathrm{O}$ bonds were belong to PSF polymer and interpreted at $1585 \mathrm{~cm}^{-1}, 1243 \mathrm{~cm}^{-1}$ and $1151 \mathrm{~cm}^{-1}$, respectively. These results were agree with the finding of Mehta and co-author and study by Karimi and co-workers. ${ }^{30,31}$ In addition, the transmittance band observed at $1490 \mathrm{~cm}^{-1}$ can be explained owing to the $\mathrm{C}-\mathrm{N}$ bond stretching vibration which proved that the presence of PVP as additive in the membrane. This transmittance band value can be related with the previous study which mentioned that the $\mathrm{C}-\mathrm{N}$ stretch value is within $1112-1595 \mathrm{~cm}^{-1} .{ }^{32}$ The similarity of infrared spectrum confirmed that PSF membranes display about same activity even after the existence of additive and surfactant.

FTIR spectrum for optimal performance membrane at $2 \mathrm{wt} \%$ of surfactant was shown in Figure 6. The FTIR spectrum in this figure does not showed significant changes compared to Figure 5 due to similar chemical solutions used as the base materials in membrane making. However, no major peak observed for SDS molecule as displayed. Yet, a C- $\mathrm{H}_{3}$ stretching at $2864 \mathrm{~cm}^{-1}$ confirmed the existence of SDS surfactant. This peak in line with the finding of Viana and co-authors which discover the stretching of $\mathrm{C}-\mathrm{H}_{3}$ group from SDS at $2873 \mathrm{~cm}^{-1} .33$

\section{Conclusion}

High selective LPRO membrane based surfactant for desalination was successfully developed. The effect of varying the concentration of SDS surfactant during the membrane formation was studied. Experimental data indicated that the small amount of surfactant (at $2.5 \mathrm{wt} \%$ of SDS in the polymeric solutions significantly improved the membrane permeability up to $44.8 \mathrm{~L} / \mathrm{m}^{2} \mathrm{~h}$ and $45.58 \mathrm{~L} / \mathrm{m}^{2} \mathrm{~h}$ for brackish water flux. Rejection data revealed that at the optimal SDS concentration $(2 \mathrm{wt} \%)$, the membrane achieved highest rejection of salt about $90.9 \%$ and $90.4 \%$ for of brackish and seawater, respectively. The fabricated membranes exhibit of asymmetrical structures with the formation of fine finger-like structure, macrovoids and number of pores on the active layer and supporting layer which enhanced the performance of membranes. Furthermore, molecular study of LPRO membrane proven that the addition of surfactant in the polymeric membrane solution provided better molecular orientation which reflected towards better performances.

\section{Acknowledgments}

None.

\section{Conflicts of interest}

The authors declared there is no conflict of interest.

\section{References}

1. Baten R, Stummeyer K. How sustainable can desalination be? Desalination Water Treat. 2013;51(1-3):44-52.

2. Sandia D. Water purification roadmap-a report of the executive committee, US Department of the interior, bureau of reclamation and sandia National laboratories. DWPR Program Report, Desalination. $2003 ; 95$.

3. Akili DK, Kutubkhanaha KI, Wie JM. Advances in seawater desalination technologies. Desalination. 2008;221(1-3 ):47-69.
4. Lee S, Elimelech M, Booa C, et al. Comparison of fouling behaviour in forward osmosis (FO) and reverse osmosis (RO). J Membrane Sci. 2010;365(1-2):34-39.

5. Sulaiman NA, Hassan AR, Rozali S, et al. Development of asymmetric low pressure reverse osmosis surfactants membrane: effect of surfactant types and concentration. Periodica Polytechnica Chemical Engineering. 2019.

6. Fritzmann C, Löwenberg J, Wintgens T, et al. State-of-the-art of reverse osmosis desalination. Desalination. 2007:216(1-3):1-76.

7. Semiat R. Energy issues in desalination processes. Environ Sci Technol. 2008;42(22):8193-8201.

8. Garud RM, Kore SV, Kore VS, et al. A short review on process and applications of RO. Universal J Environ Res Technol. 2011;1(3):233238.

9. Wenten IG. Recent development in membrane science and its industrial applications. Membrane Sci Technol. 2003;24:1-16.

10. Murthy GVP, Choudhari LB. Treatment of distillery spent wash by combined UF and RO processes. Global NEST J. 2009;11(2):235-240.

11. Ba C, Ladner DA, Economy J. Using polyelectrolyte coatings to improve fouling resistance of a positively charged nanofiltration membrane. $J$ Membrane Sci. 2010;347(1-2):250-259.

12. Guillen GR, Pan Y, Li M, et al. Preparation and characterization of membranes formed by nonsolvent induced phase separation: a review. Ind Eng Chem Res. 2011;50(7):3798-3817.

13. Voicu SI, Aldea F, Radut M, et al. Nanostructured polysulfone composite membranes. UPB Sci Bull B. 2008;70(3):39-46.

14. Chuang WY, Young TH, Chiu WY, et al. The effect of polymeric additives on the structure and permeability of poly (vinyl alcohol) asymmetric membranes. Polym. 2000;41(15):5633-5641.

15. Jung B, Yoon JK, Kim B, et al. Effect of molecular weight of polymeric additives on formation, permeation properties and hypochlorite treatment of asymmetric PAN membrane. J Membrane Sci. 2004;243:45-49.

16. Ochoa NA, Pradanos P, Palacio L, et al. Pore size distributions based on AFM imaging and retention of multidisperse polymer solutes -characterisation of polyethersulfone UF membranes with dopes containing different PVP. J Membrane Sci. 2001;187:227-237.

17. Marchese J, Ponce M, Ochoa NA, et al. Fouling behaviour of polyethersulfone UF membranes made with different PVP. J Membrane Sci. 2003;211(1):1-11.

18. Saedi S, Madaeni SS, Arabi Shamsabadi A, et al. The effect of surfactants on the structure and performance of PES membrane for separation of carbon dioxide from methane. Sep Purif Technol. 2012;99:104-119.

19. Safari NHM, Hassan AR, Che Wan Takwa CWI, et al. Deduction of surfactants effect on performance, morphology, thermal and molecular properties of polymeric polyvinylidene fluoride (PVDF) based ultrafiltration membrane. Periodica Polytechnica Chemical Engineering. 2019;63(1):27-35.

20. Ali NSM, Hassan A-R. The effect of SDS concentration on the thermal property and performance of low pressure active reverse osmosis (LPARO) membrane for brackish and seawater desalination. J Appl Sci Agric. 2015;20:510-516.

21. Hassan AR, Mohd Safari NH, Rozali S, et al. Effect of cetyle trimethyl ammonium bromide (CTAB) surfactant on nanofiltration membrane for dye removal. Malaysian J Appl Sci. 2017;2(2):29-36.

22. Rahimpour A, Madaeni SS, Mansourpanah Y. The effect of anionic, non-ionic and cationic surfactants on morphology and performance of polyethersulfone ultrafiltration membranes for milk concentration. $J$ Membrane Sci. 2007;296(1-2):110-121. 
23. Ali NSM, Hassan AR. The effect of CTAB and SDS surfactant on the morphology and performance of low pressure active reverse osmosis membrane. Malaysian J Analyt Sci. 2016;20(3):510-516.

24. Hassan AR, Sharifuddin SS, Mohd Isa MH, et al. Assessment the performance and morphological structures of asymmetric Pes/surfactant membranes for nanofiltration of dyes wastewater. J Fundam Appl Sci. 2017;9(2S):137-146.

25. Fadilah NIM, Hassan AR. Preparation, characterization and performance studies of active PVDF ultrafiltration-surfactants membranes containing PVP as additive. Adv Materials Res. 2016;1134:44-49.

26. Sofiah H, Nora'aini A, Marinah MA. The influence of polymer concentration on performance and morphology of asymmetric ultrafiltration membrane for lysozyme separation. $J$ Appl Sci. 2010;10:3325-3330

27. Razali NFB, Mohammad AW, Al Fadul S. Preparation, characterization and performance of polyethersulfone (PES)-polyaniline (PANI) blended membrane. Adv Mater Res. 2011;233:3018-3022.
28. Hassan AR, Rozali S, Safari NHM, et al. The roles of polyethersulfone and polyehtylene glycol additive on nano filtration of dyes and membrane morphologies. Environ Eng Res. 2018;23(3):316-322.

29. Zainal SH, Hassan AR, Isa MHM. The effect of polymer concentration and surfactant types on nanofiltration-surfactant membrane for textile wastewater. Malaysian J Analyt Sci. (MJAS). 2016;20:1524-1529.

30. Mehta R, Bharda PS, Sharma S, et al. Mitigation of arsenic from water through tailor-made thin film composite (TFC) membrane. MOJ Poly Sci. 2018;2(1):29-32.

31. Karimi S, Firouzfar E, Khoshchehreh MR. Assessment of gas separation properties and $\mathrm{CO} 2$ plasticization of polysulfone/ polyethylene glycol membranes. J Petrol Sci Eng. 2019;173:13-19.

32. Fadilah NIM, Hassan AR. Asymmetric PVDF ultrafiltration (UF) membranes : effect of additives \& surfactants. International $\mathrm{J}$ Chem Environ Eng. 2014;5(6):336-344.

33. Viana RB, Alb'erico da Silva BF, Andr'e SP. Infrared spectroscopy of anionic, cationic, and zwitterionic surfactants. Adv Phys Chem. 2012;2012:1-14. 